$16^{\circ}$ USIHC - Congresso Internacional de Ergonomia e Usabilidade de Interfaces Humano Computador

CINAHPA | 2017 - Congresso Internacional de Ambientes Hipermídia para Aprendizagem.

\section{ERGONOMIA E USABILIDADE EM INTERFACES DIGITAIS DE ENTRETENIMENTO}

\section{ERGONOMICS AND USABILITY IN ENTERTEINMENT DIGITAL INTERFACES}

\author{
Lígia Renault de Vilhena ${ }^{1}$, Bach; \\ Carolina Águida Lopes ${ }^{2}$, Bach; \\ Laura Mattos Cardoso Rocha ${ }^{3}$, Bach; \\ Maria Clara Marinho de Lima ${ }^{4}$, Bach; \\ Iara Sousa Castro ${ }^{5}$, D. Sc.
}

(1) Universidade do Estado de Minas Gerais e-mail: vilhenaligia@gmail.com.br

(2) Universidade do Estado de Minas Gerais e-mail: contate.agui@gmail.com

(3) Universidade do Estado de Minas Gerais e-mail: lauramcr09@gmail.com

(4) Universidade do Estado de Minas Gerais e-mail: mariaclaromarinholima@gmail.com

(5) Universidade do Estado de Minas Gerais e-mail: iarascastro@yahoo.com.br

Palavras chave: Banco de Séries, Usabilidade, Interface Digital

Apesar do crescimento da Internet como fonte de entretenimento, grande parte das plataformas digitais são de difícil navegação e pouco inclusivas. Isso demonstra uma falta de conhecimento de ergonomia visual por parte de designers e programadores, o que causa insatisfação aos usuários. Este artigo tem como objetivo analisar e identificar esses problemas, assim como propor como solucioná-los.

Keywords: Banco de Séries, Usability, Digital Interface

Despite the growth of the Internet as a source of entertainment many digital platforms are difficult to navigate and not very inclusive. This demonstrates a lack of knowledge of visual ergonomics in designers and programmers, which causes dissatisfaction among the users. The objective of this article is to analyze and identify those problems as well as to propose how to solve them. 


\section{Introdução}

Este artigo tem por objetivo analisar a qualidade ergonômica de interfaces de entretenimento, recorrendo ao estudo de caso do Banco de Séries por meio de um roteiro de tarefas, com o intuito de sensibilizar alunos de graduação do curso de design sobre a importância de se projetar, considerando o usuário no processo projetual.

O Banco de Séries é uma rede social em que os usuários podem compartilhar e comentar as séries que assistem, além de marcar as séries e episódios vistos pelos usuários, auxiliando no acompanhamento destas. Atualmente, com a ascendência de redes de televisão por streaming, como a Netflix,Amazon Prime Video, HBO Max, HBO Go, Telecine Play, iTunesStoree Google Play aumentou-se a demanda por redes como o Banco de Séries, Orangotag, TV Show Time, TrakTV e Filmow.

Tal aumento deve-se, primeiramente, ao uso recente de redes sociais digitais, que permitem a comunicação e o consequente estabelecimento de relações entre pessoas com os mesmos interesses, sem a necessidade de se encontrarem fisicamente. Mas também, ao uso do serviço de streaming, ou a distribuição de dados multimídia pela internet. A televisão por streaming permite que o telespectador assista a vídeos, séries e filmes em qualquer aparelho que se conecte a internet - smart $T V$, computador ou smartphone. Esse serviço traz flexibilidade ao usuário, porque pode ser usado de qualquer lugar e, geralmente, é mais barato que a televisão por assinatura. Segundo dados da Cisco VNI (2016), que realiza previsões do tráfego global de internet fixa e móvel, em 2020, o vídeo online será responsável $80 \%$ pelo tráfego mundial de internet.

Sendo o Banco de Séries uma rede específica para o público que assiste a esse tipo de produção, o usuário tem a certeza de que outros conectados compartilham desse interesse. Assim, além de ter a segurança de que se relacionará facilmente com outras pessoas, o usuário da interface trocará informações para eleger a série a assistir e onde localizá-la.

\subsection{Ergonomia e Usabilidade}

Ao procurar por uma plataforma de lazer e entretenimento, o usuário busca por eficiência e conforto. Com esse objetivo, ao planejar uma interface dessa natureza os projetistas de interface devem usufruir dos conceitos de ergonomia $\mathrm{e}$ usabilidade (ABRAHÃO et al., 2012).

A ergonomia "trata de desenvolver conhecimentos sobre as capacidades, limites e outras características do desempenho humano e que se relacionam com o projeto de interfaces, entre indivíduos e outros componentes" (MORAES e MONT'ALVÃO, 2000, p. 10), enquanto usabilidade significa "eficiência, facilidade, comodidade e segurança no uso dos produtos". (IIDA e BUARQUE, 2016, p.258).

Partindo desses conceitos, a interface teria uma programação visual adequada, com comandos inteligíveis, tornando-se, além de confortável, mais inclusiva. O Banco de Séries - objeto de estudo deste artigo - possui 75 mil usuários ativos atualmente, e destes, $96 \%$ tem idade entre 18 e 34 anos, ao passo que $3 \%$ possui mais de 50 anos (dados fornecidos pelo próprio provedor como feedback). Isso demonstra que, se a plataforma passasse por um estudo ergonômico, poderia ampliar seu público para outras faixas etárias, como adultos acima de 50 anos e os idosos.

Assim, as recomendações para o estudo de caso do Banco de Séries serão baseadas nas "oito regras de ouro do design de interface"(SHNEIDERMAN, 1986). Esses princípios de design de interface foram criados a partir do conceito de usabilidade para auxiliarem na concepção e na avaliação de sistemas interativos.

\section{Metodologia}

A metodologia utilizada nesta pesquisa é de natureza qualitativa (GOODE, 1969) do tipo estudo de caso (YIN, 2001). Baseada na técnica da avaliação cooperativa (MONK, 1993), foi realizado um estudo participativo a fim de se ter um feedback do usuário relativo a uma interface 
$16^{\circ}$ Ergodesign- Congresso Internacional de Ergonomia e Usabilidade de Interfaces Humano Tecnológica: Produto, Informações Ambientes Construídos e Transporte

$16^{\circ}$ USIHC - Congresso Internacional de Ergonomia e Usabilidade de Interfaces Humano Computador

CINAHPA | 2017 - Congresso Internacional de Ambientes Hipermídia para Aprendizagem. digital.

Nesse estudo há interação entre o usuário participante, a interface e o pesquisador. Os pontos positivos e negativos da interface, objeto de estudo, são identificados a partir de observações que consideram: o tempo, a habilidade e o esforço gastos pelo usuário para realizar o teste, assim como a influência do equipamento utilizado no teste.

“Ao navegar num sistema informatizado, o usuário de fato mobiliza diferentes processos cognitivos; compreender como ele os mobiliza auxilia os diferentes profissionais envolvidos no processo de concepção de um sistema informatizado. Ao integrar as características da população de usuários está, de fato, promovendo uma das formas de inclusão no mundo da informática. Portanto, incorporar princípios de usabilidade desde a fase de projeto de arquitetura do software, de forma a evitar mudanças nas fases mais avançadas de desenvolvimento do software, pode beneficiar tanto aqueles que são desenvolvedores quanto os usuários finais". (GOLDEN, 2009 apud ABRAHÃO, 2012, p.27)

Para a coleta de dados foram elaboradas etapas de trabalho que envolviam: (1) a seleção de usuários participantes com nível de habilidade similar, (2) a seleção de tarefas cognitivas básicas para a interação com a interface, (3) o preenchimento de uma pesquisa de opinião estimulada pela verbalização de problemas relacionados à interface e (4) busca de soluções para os problemas evidenciados pelo teste.

Os usuários participantes da pesquisa testariam o site e o aplicativo, a partir das tarefas previamente elaboradas pelos avaliadores, para que pudesse ser feita uma comparação entre o site e o aplicativo. A finalidade dessa comparação seria verificar se haveria interferência por parte do usuário por saber manusear, ou não, o aparelho em que o teste seria aplicado, por já conhecer a interface ou se seria o primeiro contato com ela. Também seria relevante avaliar o site e o aplicativo, pois as plataformas apresentam formatos diferentes que desencadeiam usos diferentes.
Para registrar os dados da coleta relativos à ação dos usuários foi utilizada a captura de tela e do som nos respectivos aparelhos em que as tarefas seriam realizadas. Esse recurso permitiu gravar a tela da interface durante o teste, facilitar a observação sobre como cada usuário solucionava a tarefa, registrar o tempo dedicado a sua realização e os possíveis comentários feitos pelos participantes durante esse processo.

Antes da aplicação do teste, foi realizado um teste piloto com dois usuários a fim de verificar a qualidade dos aparelhos utilizados, bem como a qualidade do áudio e da imagem dos programas de captura de tela. Durante o teste piloto foi constatado que o aplicativo do Banco de Séries, apesar de fornecer a opção de fazer login com o Facebook, não é capaz de realizar essa ação. Como precaução, foi criada uma conta na plataforma, que possibilitou efetuar o teste. Depois de verificar que o login com o Facebook não era possível, o usuário recebia o login e a senha dessa conta para continuar a pesquisa.

A tarefa - fazer login com o Facebook - não foi alterada, uma vez que, mesmo não sendo possível realizá-la, seria relevante para verificar o comportamento dos usuários diante de uma tarefa que solicitaria a elaboração de uma estratégia para contornar um problema. Os usuários do Banco de Séries que, pelo computador, realizaram login na interface, pelo Facebook teriam que criar outra conta para usar a interface pelo aplicativo. Nessa nova conta, o usuário não teria registradas as séries que acompanha ou as pessoas com quem se relaciona no Banco de Séries. Por esse motivo, optou-se por manter a tarefa e expor o erro aos usuários participantes.

A pesquisa foi executada em $2016 \mathrm{com} \mathrm{dez}$ usuários participantes com idade entre 18 e 28 anos, entre estes alunos e professores de uma Escola de Design universitária.

A escolha dos usuários selecionados foi pautada no objetivo da pesquisa - relativa à sensibilização de alunos do curso de Design Gráfico. 
$16^{\circ}$ USIHC - Congresso Internacional de Ergonomia e Usabilidade de Interfaces Humano Computador

CINAHPA | 2017 - Congresso Internacional de Ambientes Hipermídia para Aprendizagem.

\section{Pesquisa de Opinião}

\begin{tabular}{|l|r|r|r|r|r|r|r|r|r|r|}
\hline Usuário: & 1 & 2 & 3 & 4 & 5 & 6 & 7 & 8 & 9 & 10 \\
\hline Idade & 28 & 20 & 24 & 22 & 27 & 19 & 19 & 18 & 27 & 21 \\
\hline Gosta de assistir séries? & & & & & & & & & & \\
\hline Já conhecia o aplicativo? & & & & & & & & & & \\
\hline Já conhecia o site? & & & & & & & & & & \\
\hline Já utiliza algum deles? Qual? & & & & & & & & & & \\
\hline Se não, acha que o app/site seria útil? & & & & & & & & & & \\
\hline $\begin{array}{l}\text { Tem familiaridade com o } \\
\text { equipamento? }\end{array}$ & & & & & & & & & & \\
\hline Usaria o aplicativo novamente? & & & & & & & & & & \\
\hline Usaria o site novamente? & & & & & & & & & & \\
\hline
\end{tabular}

Tabela 1 -Respostas dos usuários participantes. A cor vermelha indica respostas "não" e a cor verde as respostas "sim".

A tabela 1 apresenta as respostas dos usuários, participantes dos testes realizados. Os quadrados vermelhos apontam a resposta negativa e os quadrados verdes indicam a resposta positiva. É importante ressaltar que na tabela constam somente as perguntas de resposta objetiva.

Os aparelhos utilizados para a aplicação dos testes foram os mesmos para todos os usuários e possuíam as seguintes características: um smatphone SAMSUNG Galaxy S5 Mini - sistema operacional Android 4.4.2 TouchWiz UI KitKat 4.5 polegadas, processador $1.4 \mathrm{GHz}$ Quad Core e um notebook SAMSUNG Ultrabook NP530U3B sistema operacional Windows 10 , processador Intel Core i5, 13,3 polegadas. Os respectivos programas para captura de telas utilizadas foram AZ Screen Recorder versão 4.6, para Android, e Camstudio versão 2.7, para Windows. Ambos os programas são recomendados e específicos para esses sistemas operacionais.

\section{Estudo de Caso}

\subsection{Interface}

O Banco de Séries é uma rede social, criada em 2012 por Alex Palombo, disponível nos formatos de site e aplicativo para smartphones - na iStore ou no Google Play. A interação entre os usuários é a principal finalidade da rede, uma vez que há espaços reservados para rankings de episódios e séries, classificações e categorias especiais, feitos com base naquilo que os membros estão comentando e curtindo.

O Banco de Séries, entretanto, não serve para assistir séries, é contra a pirataria e não disponibiliza nenhum conteúdo que fere os direitos autorais. É apenas uma rede social em que fãs de séries podem comentar e compartilhar conteúdos, organizar sua programação e serem notificados de novos acontecimentos ou conteúdos na interface.

Ao entrar no Banco de Séries é preciso fazer um cadastro ou fazer login com o Facebook e montar uma grade de séries que o usuário assiste ou gostaria de assistir. Ao pesquisar por uma série, a interface oferece informação ao usuário sobre onde a série é disponibilizada ao público, qual é a avaliação atribuída por outros usuários, qual é o gênero, entre outros dados. Há também uma lista de episódios divididos por temporada e sugestões de séries semelhantes, caso o usuário se interesse em ampliar sua grade de programação.

O usuário também pode marcar quando avança um episódio, se quer assisti-lo imediatamente ou colocá-lo em espera. Além disso, ao seguir uma série, o usuário pode ter contato com outras 


\section{$16^{\circ}$ \\ ERGODESIGN USIHC CINAHPA}

$16^{\circ}$ Ergodesign- Congresso Internacional de Ergonomia e Usabilidade de Interfaces Humano Tecnológica: Produto, Informações Ambientes Construídos e Transporte

$16^{\circ}$ USIHC - Congresso Internacional de Ergonomia e Usabilidade de Interfaces Humano Computador

CINAHPA | 2017 - Congresso Internacional de Ambientes Hipermídia para Aprendizagem. pessoas que compartilham a sua preferência. Assim, a interface proporciona um chat para que os fãs possam debater e comentar os programas vistos.

\subsection{Tarefas}

Segundo ABRAHÃO, et al., (2009, p.49), "no seu sentido clássico, a tarefa é entendida como um conjunto de prescrições, com relação àquilo que o trabalhador deve fazer (...)". Nesta pesquisa foram dadas quatro tarefas de caráter cognitivo - busca e armazenamento de informações, tomada de decisões - a serem realizadas pelos usuários em ambas as plataformas.

As tarefas consistiam em: (a) fazer login com o Facebook, (b) procurar por uma série, (c) colocar a série pesquisada na grade de programação e (d) remover a série da grade de programação.

A realização dessas tarefas possuem formas diferentes de serem feitas no site e no aplicativo. Elas serão explicadas a seguir.

\subsubsection{Site}

a) Tarefa 1 - Fazer login com o Facebook

Clicar em login no centro superior da tela (Figura 1). Essa ação abre uma caixa de diálogo em que o usuário deve clicar no ícone do Facebook, que se encontra no centro inferior. Uma segunda caixa de diálogo é aberta (Figura 2) onde o usuário deve digitar suas informações de login do Facebook - email e senha - e clicar em enter.

\section{b) Tarefa 2 - Procurar por uma série}

Selecionar a opção Pesquisar localizado na barra de tarefas (Figura 3). O usuário deve digitar o nome de uma série e selecioná-la. A seguir o usuário é redirecionado para a página principal da série.

\section{Página Inicial do Site}

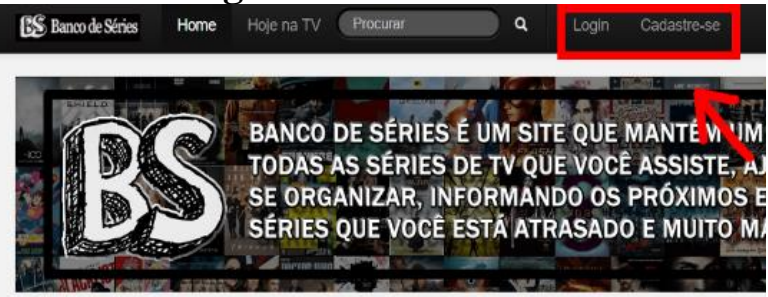

IMPORTANTE: O Banco de Séries nẫo serve para assistir séries! Somos uma rede social onde os fãs de séries podem controlar os episodilos que assistiram, dar notas, comentar, criar sua agenda, saber quando passa o próximo episódlio. Somos totalmente contra a piratarn
diretios autorais.

Figura 1 - Local de fazer login na página inicial do site

Fonte: Página inicial do site www.bancodeseries.com.br.

\section{Caixa de diálogo - Login com o Facebook}

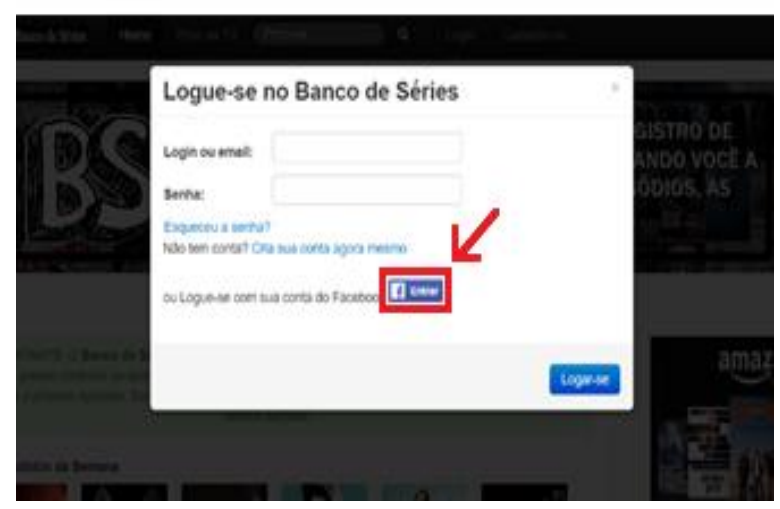

Figura 2-A caixa de diálogo é aberta ao clicar em login.

Fonte: Página inicial do site www.bancodeseries.com.br.

c) Tarefa 3 - Colocar a série pesquisada na grade de programação

Página inicial da conta do usuário no site

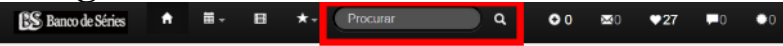

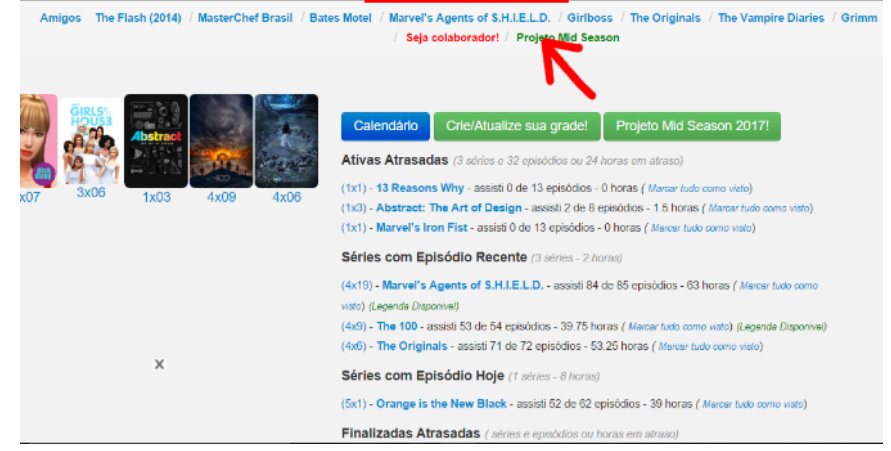

Figura 3-Indicação da caixa de pesquisa.

Fonte: Página inicial do site www.bancodeseries.com.br
Realização:

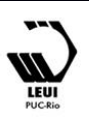




\section{$16^{\circ}$ \\ ERGODESIGN USIHC CINAHPA}

$16^{\circ}$ Ergodesign- Congresso Internacional de Ergonomia e Usabilidade de Interfaces Humano Tecnológica: Produto, Informações Ambientes Construídos e Transporte

$16^{\circ}$ USIHC - Congresso Internacional de Ergonomia e Usabilidade de Interfaces Humano Computador

CINAHPA | 2017 - Congresso Internacional de Ambientes Hipermídia para Aprendizagem.
A figura 4 indica o local, na página inicial da série, que o usuário pode selecionar, a opção Adicionar na minha grade por meio de um retângulo azul, no canto esquerdo abaixo da foto de capa da série.

\section{Página Inicial da Série no site}

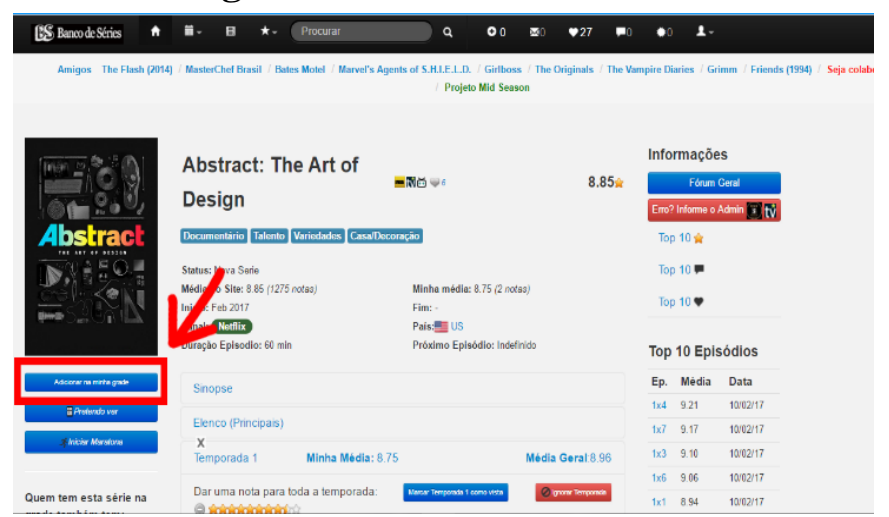

Figura 4-Indicação do local para colocar a série pesquisada na grade

Fonte: Página inicial do site www.bancodeseries.com.br

d) Tarefa 4 - Remover a série da grade de programação

A figura 5 indica o local de clicar na opção Cancelar da minha grade. Trata-se do mesmo botão utilizado para Adicionar na minha grade, porém sua função é oposta e a cor é alterada do azul para o vermelho para completar o teste.

\section{Página Inicial da Série no site}

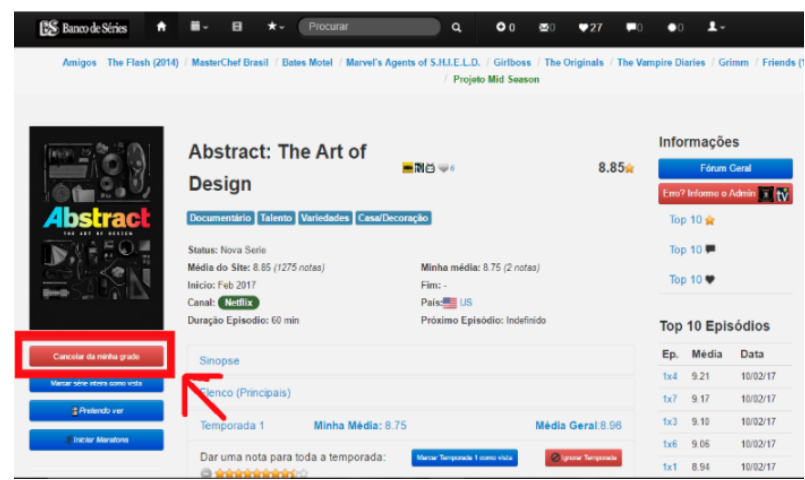

Figura 5 - Indicação do local para remover a série da grade da programação

Fonte: Página inicial do site www.bancodeseries.com.br

\subsubsection{Aplicativo}

a) Tarefa 1 - Fazer login com o Facebook

A figura 6 mostra o local para o usuário selecionar o ícone do Facebook encontrado no

centro inferior da tela. Ao clicar nele, uma caixa de diálogo é aberta e o usuário deve digitar suas informações de login do Facebook - e-mail e senha - e clicar em enter.

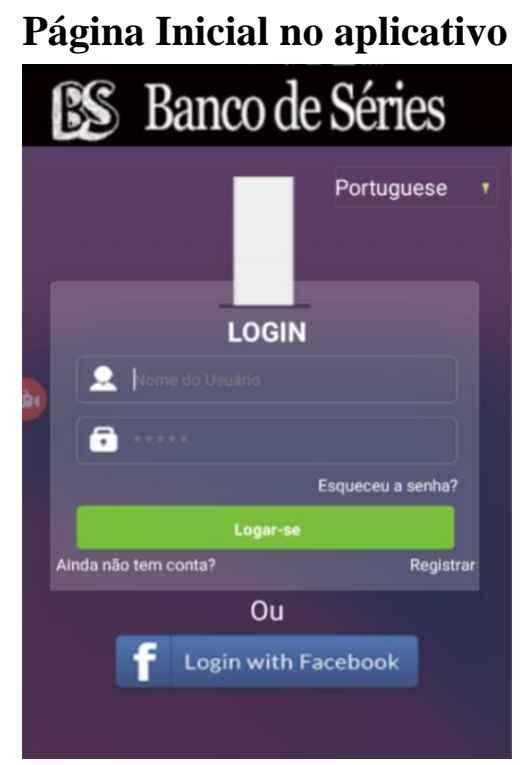

Figura 6 -Ícone para acessar o Facebook na Página inicial do Banco de série, Fonte: Aplicativo Banco de Series, disponível na iStore e Google Store.

b) Tarefa 2 - Procurar por uma série

A figura 7 mostra, na página inicial do usuário, o ícone de pesquisa - lupa - no canto superior direito da tela. O usuário deve clicar na lupa e ser redirecionado para uma página de pesquisa na qual pode digitar o nome de uma série a sua escolha. A página filtra séries com nomes similares ao digitado e, dentre estes, o usuário deve selecionar a série que escolheu. Após essa ação o usuário é redirecionado para a página principal da série. 


\section{$16^{\circ}$ \\ ERGODESIGN USIHC CINAHPA}

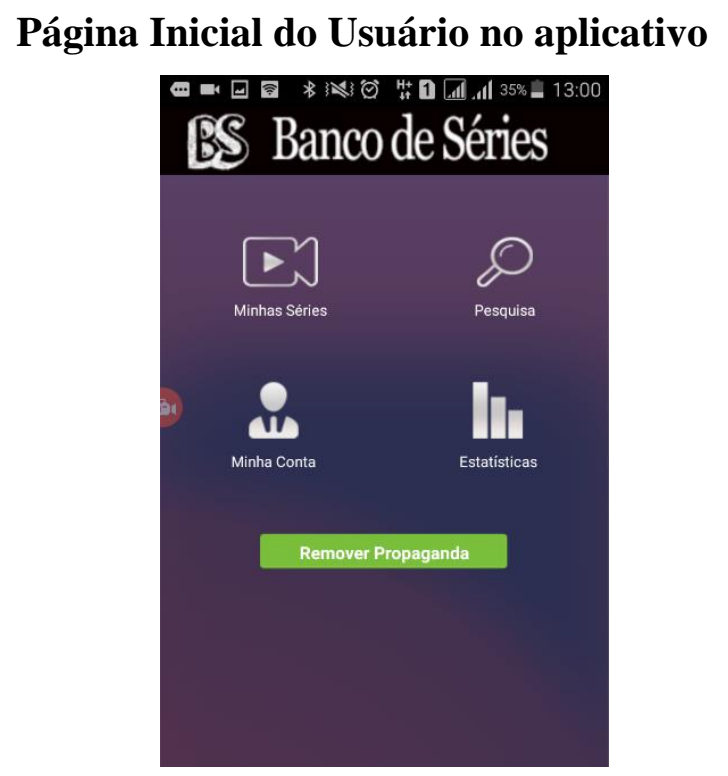

Figura 7 - Página principal da série Fonte: Aplicativo Banco de Series disponível na iStore e Google Store.

c) Tarefa 3 - Colocar a série pesquisada na grade de programação

A figura 8 indica que para selecionar, na página principal, a opção Adicionar na grade, deve-se clicar o ícone em vermelho no canto superior direito.

\section{Página Principal da Série no aplicativo}

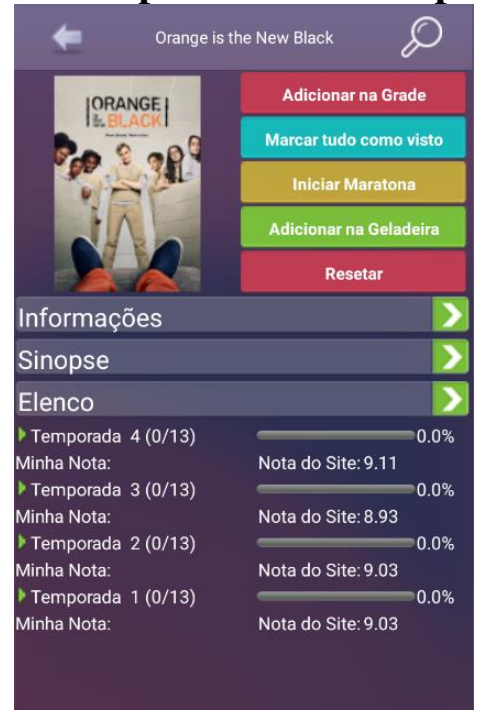

Figura 8 - Página principal da série Fonte: Aplicativo Banco de Series, disponível na iStore e Google Store. $16^{\circ}$ Ergodesign- Congresso Internacional de Ergonomia e Usabilidade de Interfaces Humano Tecnológica: Produto, Informações Ambientes Construídos e Transporte

$16^{\circ}$ USIHC - Congresso Internacional de Ergonomia e Usabilidade de Interfaces Humano Computador

CINAHPA | 2017 - Congresso Internacional de Ambientes Hipermídia para Aprendizagem.

d) Tarefa 4 - Remover a série da grade de programação

A figura 9 indica o local de clicar na opção Remover da grade - o botão é o mesmo de Adicionar na grade, porém a sua função altera-se para completar o teste.

\section{Página Principal da Série no aplicativo}

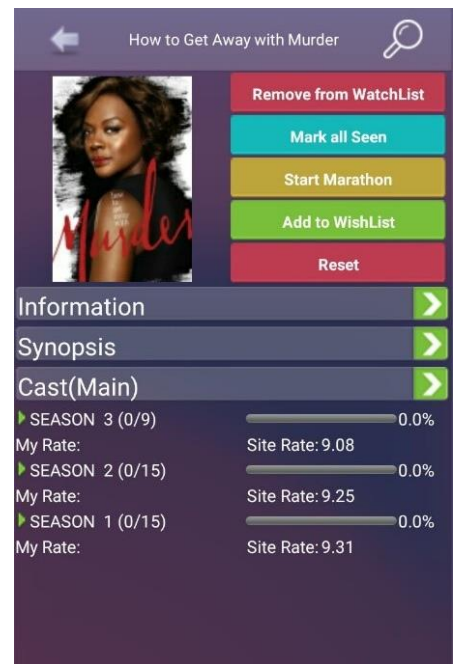

Figura 9 - Indicação de clicar na opção remover da grade na página principal da série,

Fonte: Aplicativo Banco de Series, disponível na iStore e Google Store.

\subsection{Resultados}

Os resultados revelam que os usuários

demonstraram maior facilidade e satisfação com a interface do Banco de Séries no aplicativo quando comparado ao site. Em média, foram 2 minutos e 56 segundos para completar os testes no aplicativo, e 3 minutos e 3 segundos no site. Cabe ressaltar que o resultado não foi alterado pela falta de familiaridade dos usuários com os aparelhos utilizados, uma vez que a parcela das pessoas que não apresentavam familiaridade representava apenas $20 \%$ da população total, além do site e aplicativo serem testados antes de começar o teste.

a) Tarefa 1 - Fazer login com o Facebook.

Ainda de acordo com o tempo, no aplicativo, a 


\section{$16^{\circ}$ \\ ERGODESIGN USIHC CINAHPA}

$16^{\circ}$ Ergodesign- Congresso Internacional de Ergonomia e Usabilidade de Interfaces Humano Tecnológica: Produto, Informações Ambientes Construídos e Transporte

$16^{\circ}$ USIHC - Congresso Internacional de Ergonomia e Usabilidade de Interfaces Humano Computador

CINAHPA | 2017 - Congresso Internacional de Ambientes Hipermídia para Aprendizagem. tarefa mais difícil permaneceu sendo a primeira fazer login com o Facebook, que levou 1 minuto e 13 segundos, em média - constatou-se que não é possível realizar esta tarefa sem um login e senha independentes do Facebook. Segundo um usuário, "Parece que não dá pra logar com o Facebook, pois dá uma mensagem de erro". Surge uma caixa de diálogo na tela informando ao usuário que houve erro de conexão e este é enviado de volta a tela inicial.

\section{Mensagem de erro}

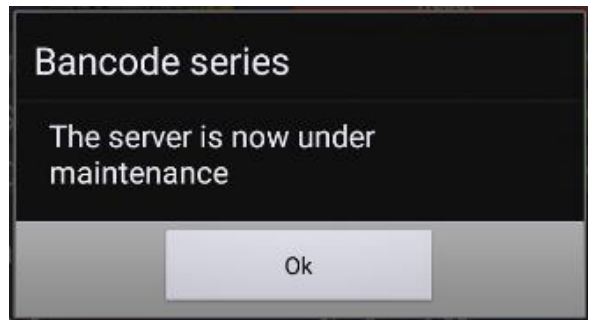

Figura 10-Caixa de diálogo encontrada no aplicativo Banco de Series, que diz "O servidor está em manutenção”.

b) Tarefa 2 - Procurar por uma série.

No site, a tarefa mais difícil foi pesquisar a série. Quando o título da série é digitado, ele fornece a opção de preenchimento automático. Porém, quando se clica nesta opção, o usuário não é direcionado para a página principal da série, mas continua na página de pesquisa.

c) Tarefa 3 - Colocar a série na grade de programação.

Após encontrar a página principal da série, a terceira tarefa revelou ser a menos complexa. A opção de Adicionar na grade tem a terminologia correta e está próxima à foto da série. Tal imagem chama mais a atenção na página devido ao seu dimensionamento e a opção tem boa proporção em relação a esta foto, ou seja, também apresenta uma boa proporção para visualização.

d) Tarefa 4 - Remover a série da grade de programação.

A tarefa de remover a série também se mostrou simples, mas gerou certa confusão, porque no site está escrito Cancelar da minha grade. Porém, quando o botão é clicado, a série aparece na aba de abandonadas, um erro de terminologia.

\subsection{Percepção do site pelos usuários}

Durante a realização do teste, os usuários evidenciaram opiniões relativas à comparação entre usar a interface por meio do auxílio do aplicativo e do site:

O gráfico 1 ilustra que todos os usuários concordaram que o aplicativo e o site apresentam diferenças. Percentualmente, $50 \%$ deles avaliaram que o aplicativo é melhor que o site, enquanto $10 \%$ preferiram o site e $40 \%$ desgostaram de ambos. Quanto ao layout, 60\% dos usuários concordaram que o aplicativo não apresentou problemas, enquanto $70 \%$ dos usuários afirmou que o layout do site é insatisfatório.

\section{Preferência de Plataforma}

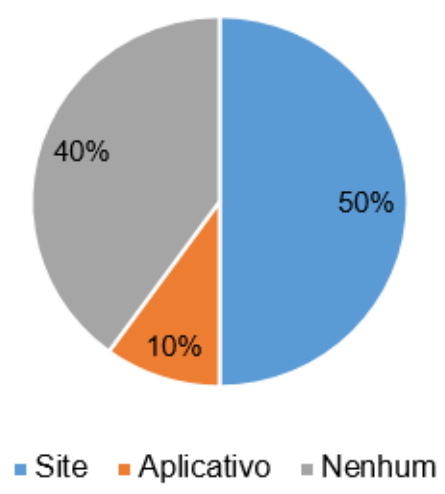

Gráfico 1 - Preferência da Plataforma.

"No aplicativo as informações estão bem localizadas. No site, as letras são pequenas e não há hierarquização entre os botões, por causa disso, há defeitos de layout." (Usuário 
$16^{\circ}$ Ergodesign- Congresso Internacional de Ergonomia e Usabilidade de Interfaces Humano Tecnológica: Produto, Informações Ambientes Construídos e Transporte

$16^{\circ}$ USIHC - Congresso Internacional de Ergonomia e Usabilidade de Interfaces Humano Computador

CINAHPA | 2017 - Congresso Internacional de Ambientes Hipermídia para Aprendizagem.
$1)$.

"Não gostei do layout, parece ABNT, muito formal." (Usuário 10).

Mesmo havendo uma preferência do aplicativo em relação ao site, os usuários reclamaram do primeiro em relação às propagandas e ao tamanho dos botões na tela.

"Os botões são muito pequenos, difíceis de
clicar." (Usuário 8)

"Podia ter um feedback quanto as

propagandas, a aba da internet abre do nada

e você nem sabe o que é aquilo." (Usuário 2).

Durante os testes com o aplicativo, periodicamente, uma aba da internet abria revelando uma propaganda. Isso acontecia depois do usuário realizar um comando na interface, fazendo parecer que aquela aba que se abria fazia parte do comando.

Outro defeito identificado pelos usuários no aplicativo foi o idioma. Inicialmente o aplicativo está em inglês e, mesmo selecionando a opção de tradução, apenas algumas palavras são traduzidas. Segundo os usuários isso prejudica a usabilidade, especialmente pelo fato de o Banco de Séries ser uma interface brasileira.

"Detesto coisa que não tem tradução, porque acho que nem todo mundo sabe inglês e eu acho que dificulta muito, principalmente pelo fato de os termos do aplicativo serem incomuns." (Usuário 10).

90\% da população participante não conhecia ainda a interface, mostrando que a falta de familiaridade com ela influencia negativamente a percepção inicial dos usuários. Isso significa que há um problema na divulgação da interface na rede.

Apesar das reclamações dirigidas ao Banco de Séries, $70 \%$ dos usuários afirmaram que utilizariam o site ou o aplicativo novamente e todos acharam que o software seria útil para eles, pois gostavam de assistir séries. Porém, nenhum dos membros da população de usuários conhecia o Banco de Sériesantes da realização da avaliação desta interface.

Estes dados reafirmam a alta demanda por uma rede social como esta, e que o Banco de Séries é uma entre poucas interfaces que apresenta essa proposta atualmente. Constatou-se a necessidade de tornar mais fácil o uso dessas interfaces.

\subsection{Recomendações}

As recomendações para os problemas encontrados no estudo de caso foram fundadas nas "oito regras de ouro do design de interface (SHNEIDERMAN, 1986).

O primeiro princípio de Shneiderman (1986), é relativo à consistência de uma interface.Afirma que sequências de ações devem se repetir em situações semelhantes. Além disso,terminologias, cores e fontes devem ser padronizadas.

Em relação a tal princípio, a interface do site e do aplicativo deveria ser semelhante. As cores, o layout e as fontes empregadas no site e no aplicativo diferem-se, não atribuindo consistência, ou identidade visual, ao Banco de Séries. As terminologias também não apresentam um padrão. No aplicativo a mesma opção é escrita "Remover da grade", enquanto no site a opção é escrita "Cancelar da minha grade". Ainda no site, as séries "canceladas" são mostradas na aba de "abandonadas". O ideal seria criar uma identidade visual e modificar a escrita, uniformizando-a.

Fizeram outras observações quanto a fonte e a escrita, respectivamente: as letras e os botões de ação são pequenos e, em relação ao aplicativo, os termos estão em inglês. Esses aspectos contrariam o princípio da usabilidade universal, ou seja, reconhecer as necessidades e diferenças entre os usuários. Segundo ABRAHÃO et al. (2012, p.29), "Na perspectiva ergonômica, a usabilidade da interface é entendida como a sua facilidade de uso, assim como a sua adequação às características dos usuários, aos seus objetivos e às exigências técnicas e organizacionais da tarefa (...)". 
$16^{\circ}$ Ergodesign- Congresso Internacional de Ergonomia e Usabilidade de Interfaces Humano Tecnológica: Produto, Informações Ambientes Construídos e Transporte

$16^{\circ}$ USIHC - Congresso Internacional de Ergonomia e Usabilidade de Interfaces Humano Computador

CINAHPA | 2017 - Congresso Internacional de Ambientes Hipermídia para Aprendizagem.
Pessoas com limitações visuais, como presbiopia (perda do poder de distinguir, com nitidez, objetos próximos, distúrbio que se observa na velhice), devido ao tamanho reduzido dos botões e da fonte, teriam dificuldades de explorar a interface, assim como os usuários que não compreendem a língua inglesa teriam dificuldades com o aplicativo. $\mathrm{O}$ aumento de tamanho da fonte do texto facilitaria a leitura das opções. O idioma Português seria mais apropriado por ser o mesmo da interface utilizada. Adotar esse idioma tornaria a interface mais atrativa ao público nativo. Contudo, seria interessante oferecer ao usuário a mudança de idioma para traduzir a interface.

Outro princípio do design de interfaces é aquele do feedback informativo. Para cada comando deve haver um feedback que informe ao fim de um comando. A mudança da apresentação dos ícones da página pode evidenciar isso.

Durante o teste, os usuários tiveram um feedback informativo, após cada tarefa, eram redirecionados para novas páginas com novo ícones. Entretanto, entre a terceira e quarta tarefas, o botão -

"Adicionar na grade" - oferece comandos distintos - alterando-se para "Remover da grade". No site, sua terminação e cor se alteram, ao passo que, no aplicativo, apenas a terminação se altera. Seria interessante que texto e coloração se comportassem igualmente.

Ainda segundo Shneiderman (1986), os projetistas de interface devem criar um sistema de tal forma a impedir que os usuários cometam erros. Se cometido, a interface deve detectar o erro, comunicar e instruir o usuário a como revertê-lo.

Ao longo do teste também foi constatado que é impossível realizar login com o Facebook pelo aplicativo. O sistema foi projetado com um erro e, apesar de o usuário ser notificado, o programa não oferece uma solução, o usuário deve descobrir o erro e como proceder. Isso foge ao princípio de evitar erros de projeção. O aplicativo do Banco de Séries precisa ser reprogramado de forma a reparar o erro ou não possibilitar a opção de login com a rede social.
Outro problema identificado durante a segunda tarefa do teste é o seguinte: ao pesquisar pela série, o site realiza a busca por preenchimento automático. Mas, quando o usuário clica sobre o nome da série, ele não é diretamente encaminhado para a página principal. Uma solução para a tarefa seria clicar no ícone de pesquisa - a lupa - ao lado da barra de tarefas, que levaria à página de seleção da série e, posteriormente, à página principal. Ainda seria possível clicar em enter após digitar a série escolhida, assim, o usuário também seria encaminhado à página.

\section{Considerações Finais}

Este artigo teve como principal finalidade demonstrar a importância da usabilidade e da ergonomia na estruturação de interfaces. A técnica da avaliação cooperativa demonstrou-se eficaz nesse sentido, uma vez que os usuários verbalizam diretamente aos projetistas o que os provoca desconforto durante o uso da interface.

Foi constatado que, para que uma interface seja considerada boa, ela deve ser eficiente, atendendo às necessidades e limitações dos usuários. Tornar a interface mais simples e confortável para navegar é imprescindível a todas plataformas digitais, porém especialmente àquelas relativas a entretenimento, em que o usuário procura por um momento de lazer e bem-estar.

Por meio da pesquisa realizada com o estudo de caso observou-se que o Banco de Séries não pode ser apontado ainda como uma boa interface. Entretanto, comprovou-se que plataformas como essa, que combinam entretenimento à rede social, são altamente procuradas por usuários. Dessa maneira, certificou-se que o Banco de Séries especificamente, atenderia um público maior se sofresse uma readequação baseado nas premissas da ergonomia e da usabilidade.

Tendo isso em vista e considerando os resultados individuais dos questionários realizados, foram disponibilizadas soluções para os problemas de qualidade ergonômica encontrados, tais como princípios de design de interfaces baseados em usabilidade. Suas possíveis aplicabilidades foram 


\section{$16^{\circ}$ \\ ERGODESIGN USIHC CINAHPA}

$16^{\circ}$ Ergodesign- Congresso Internacional de Ergonomia e Usabilidade de Interfaces Humano Tecnológica: Produto, Informações Ambientes Construídos e Transporte

$16^{\circ}$ USIHC - Congresso Internacional de Ergonomia e Usabilidade de Interfaces Humano Computador

CINAHPA | 2017 - Congresso Internacional de Ambientes Hipermídia para Aprendizagem.

resumidamente explicadas, esclarecendo a eficiência destes princípios na criação de plataformas digitais.

Destaca-se, portanto, a relevância desse artigo no design de interfaces. Em outras palavras, os resultados disponibilizados podem ser aproveitados por designers que pretendem trabalhar na área de idealização de interfaces, tais como aplicativos, sites e softwares.

\section{Referências Bibliográficas}

ABRAHÃO, Júlia.; SZNELWAR, L.; SILVINO, A; SARMET, M.; PINHO, D. Introdução à

ergonomia: da prática à teoria. São Paulo: Blucher, 2009. 240p.

ABRAHHÃO, J; MONTEDO, U.; MASCIA, F.; FLEURY, A.; SANTOS, H. Ergonomia e usabilidade: em ambiente virtual de aprendizagem. São Paulo: Blucher, 2012. 101p.

BANCO DE SÉRIES. Disponível em:

<https://bancodeseries.com.br/>. Acessoem:

$21 / 11 / 2016$.

CISCO VISUAL NETWORKING INDEX. White

Paper: Cisco VNI Forecast andMethodology, 2015-2020.2016.Disponível em:

<http://www.cisco.com/c/en/us/solutions/collateral/ service-provider/visual-networking-indexvni/complete-white-paper-c11-481360.html $>$. Acesso em: 14/03/2017.

GOODE, W. J.; HATT, P. K. Métodos em pesquisa social. $3^{\mathrm{a} e d ., ~ S a ̃ o ~ P a u l o: ~ C i a ~ E d i t o r a ~}$ Nacional, 1969.

IIDA, Itiro. BUARQUE, Lia. Ergonomia: projeto e produção. $3^{\mathrm{a}}$ ed. São Paulo: Blucher, 2016. 850p.

MONK, Andrew; WRIGHT, Peter; HABER, Jeanne; DAVENPORT, Lora. Improving your human-computer interface: a practical technique. New York: Prentice Hall, 1993.

MORAES, Anamaria; MONT’ALVÃO, Cláudia.

Ergonomia: conceitos e aplicações. Rio de Janeiro: 2AB, 2000. 136p.
SHNEIDERMAN, B., PLAISANT, C., COHEN, M., JACOBS, S., and Elmqvist, N. Designing the user interface: Strategies for effective humancomputer interaction. $6^{\mathrm{a}}$ ed., Pearson, 2016.

TOMAÉL, M., ALCARÁ, A.; CHIARA, I. Das redes sociais à inovação. Disponível em: <http://www.scielo.br/pdf/ci/v34n2/28559.pdf/>. Acesso em: 08/03/2017.

YIN, Robert K. Estudo de Caso: planejamento e métodos. 4aed., Porto Alegre: Bookman, 2010.

\section{Agradecimentos}

Agradecimentos à colaboração do fundador do Banco de Séries, Alex Palombo. 